\title{
INVESTIGATION OF THE INHIBITIVE PROPERTIES OF MANGIFERA INDICA (MANGO) SEED EXTRACT ON TIN METAL CORROSION IN ACID MEDIUM
}

\author{
Ekeke, I. C., Osoka, E. C., Maduabuchi, S. A., Anyikwa, S. O., Ahizi, A. E \\ Chemical Engineering Department, \\ Federal University of Technology, Owerri, Nigeria
}

\begin{abstract}
The ability of Mangifera indica seed extract to inhibit the corrosion of tin metal immersed in $0.5 \mathrm{M} \mathrm{HCl}$ acid using the gravimetric method, in the form of a prolonged test and a rapid test at room temperature was studied. The prolonged test was carried out over a period of 21 days at two (2) days intervals, while the rapid test was performed for 5 hours at intervals of 1hour. The experiments were performed with inhibitor concentrations of $0.2 \mathrm{~g} / \mathrm{l}, 0.4 \mathrm{~g} / \mathrm{l}, 0.6 \mathrm{~g} / \mathrm{l}, 0.8 \mathrm{~g} / \mathrm{l}$ and $1.0 \mathrm{~g} / \mathrm{l}$. Results showed that, for the prolonged test, a maximum inhibition efficiency of $97.4944 \%$ at $1.0 \mathrm{~g} / \mathrm{l}$ concentration was obtained and the adsorption of the extract on the metal obeyed the Langmuir adsorption isotherm, whereas for the rapid test, a maximum inhibition efficiency of $84.2294 \%$ was obtained and the adsorption of the extract on the metal followed the Freundlich adsorption isotherm. Both isotherms confirm the mechanism of physisorption.
\end{abstract}

Keywords- Mangifera indica, Gravimetric, Tin Metal Corrosion, Inhibition.

\section{INTRODUCTION}

A large number of organic compounds have been studied and are still being studied to assess their corrosion inhibition potentials [1]. However, most of these substances are not only expensive but also pose health and environmental hazards prompting the search for their replacement. Plants have been recognized as sources of naturally occurring compounds that are generally referred to as 'green' compounds, some with rather complex molecular structures and having a variety of physical, chemical and biological properties. A number of these compounds are usually used in traditional applications such as pharmaceuticals and biofuels. Furthermore, there has been a growing trend in the use of natural products as corrosion inhibitors for metals in various corrosive media.

In fact, plants have become important as environmentally acceptable, readily available and renewable sources of a wide range of chemicals. Due to bio-degradability, eco-friendliness, low cost and easy availability, the extracts of some common plant-based chemicals and their by-products have been tried as inhibitors for metals under different environments [2, 3, 4, 5]. Research has shown that some parts of Mangifera indica plant are quite effective as inhibitors of corrosion on some metals. The inhibitive effects of the bark and leaf extracts of Magnifera indica on mild steel in $0.2 \mathrm{M}$ sulfuric acid at ambient temperature has been reported [6]. The effect of extracts of Mangifera indica leaves and bark on the corrosion of mild steel test specimen immersed in $0.1 \mathrm{M} \mathrm{HCl}$ at ambient temperature has also been investigated [7]. The inhibitive effects of the aqueous extracts of mango and orange peels as green inhibitors for carbon steel in hydrochloric acid solution were reported in [8]. A study [9] on the possibility of using Mangifera indica leaves extracts as inhibitor on the corrosion of zinc sheet in $5 \mathrm{M} \mathrm{H}_{2} \mathrm{SO}_{4}$ solution has been carried out. Examination of the corrosion inhibition of mild steel using Mangifera indica seed extract in different aqueous media has also been reported [10].

Further literature search $[11,12,13,14]$ has revealed that the inhibition of corrosion on tin metal by the use of Mangifera indica seeds extract has not been widely reported. This paper therefore elucidates findings from works done in that regard.

\section{EXPERIMENT AND RESULT}

\section{A. Material preparation}

Tin metal coupons were obtained from the Mechanical Engineering department workshop of Federal University of Technology, Owerri (FUTO), Imo State, Nigeria. The metal coupons with dimensions $3 \times 3 \times 0.2 \mathrm{~cm}$ were smoothened with sand paper and then cleaned by brushing using acetone. The coupons were then weighed before being immersed into the acidic medium.

\section{B. Extract Preparation}

The mango seeds were obtained from the mango trees within FUTO premises. The outer shells were removed to obtain the seeds which were cut into chips, and then dried using a drying oven at a temperature of $101^{\circ} \mathrm{C}$ for three days. The already 
dried seeds were ground further into powder using a mechanical grinder. Two hundred grams (200g) of the ground seed were dissolved in $200 \mathrm{ml}$ of ethanol in a round bottom flask and placed in a reflux set up. The extraction process was carried out using a reflux apparatus which consists of a heating mantle where the round bottom flask containing the mixture was placed. The upper part of the setup consists of a condenser with water inlet and outlet which is tightly fitted to the mouth of the round bottom flask. The heating mantle was then turned on with the temperature set at $100^{\circ} \mathrm{C}$. The timer was switched on as soon as the mixture began to boil and the setup was left to stand for two hours before it was turned off and the mixture allowed cooling. The cooled mixture was filtered and the filtrate (extracted solvent) stored in a jar.

\section{Gravimetric or Weight Loss Method Prolonged test}

The coupons were weighed using electronic weighing balance and their initial weights recorded. Coupons of comparable weights were selected for the experiment. Two (2) coupons were suspended (aided by ropes and hooks) in one plastic container containing $400 \mathrm{ml}$ of blank solutions of $0.5 \mathrm{M} \mathrm{HCl}$ at room temperature. Seed extracts with concentrations of $0.2 \mathrm{~g} / \mathrm{L}, 0.4 \mathrm{~g} / \mathrm{L}, 0.6 \mathrm{~g} / \mathrm{L}, 0.8 \mathrm{~g} / \mathrm{L}$ and $1 \mathrm{~g} / \mathrm{L}$ were each injected into $400 \mathrm{ml}$ of the $0.5 \mathrm{M} \mathrm{HCl}$ acid solution contained in five different containers with two (2) separate coupons suspended in each of the containers. They were withdrawn from the containers at 2 days interval progressively for 21 days. At each interval, each coupon was washed, scrubbed with bristle brush in ethanol, dried in acetone and reweighed. Their new weights were recorded. The weight loss of each coupon was evaluated and recorded as the difference between its initial and new weights. The average weight loss was computed.

Evaluation of weight loss, corrosion rate, surface coverage and Inhibition efficiency

Weight loss was calculated according to the equation

$\Delta W=W_{0}-W_{f}$

where $\Delta W=$ weight loss $(g)$

$W_{o}=$ initial weight $(g)$,

$W_{f}=$ final weight $(g)$

The corrosion rate, $C R$ for each case was evaluated as the weight loss of the coupon per unit area, per unit time of exposure, i.e.

$$
C R=\frac{\Delta W}{A * t}
$$

where $C R=$ corrosion rate $\left(\frac{g}{\mathrm{~cm}^{2} d a y}\right)$

$A=$ area of coupon $\left(\mathrm{cm}^{2}\right), t=$ time (day)

The surface coverage, $\theta$ is given by equation (3)
$\theta=\frac{C R_{\text {blank }}-C R_{\text {inh }}}{C R_{\text {blank }}}$

3.

where $\quad C R_{\text {blank }}=$ corrosion

rate of solution without inhibitor $\left(\frac{g}{\mathrm{~cm}^{2} d a y}\right)$

$C R_{\text {inh }}=$ corrosion

rate of solution with inhibitor $\left(\frac{g}{\mathrm{~cm}^{2} \text { day }}\right)$

Inhibition efficiency $I . E(\%)$ is given by equation (4)

I. $E=\frac{C R_{\text {blank }}-C R_{\text {inh }}}{C R_{\text {blank }}} \times 100$

4.

\section{Rapid Test}

The experiment was carried out using a corrosion studies kit. Two tin metal coupons each were weighed and immersed in $400 \mathrm{ml}$ of $0.5 \mathrm{M} \mathrm{HCl}$ solutions containing various concentrations $(0.2 \mathrm{~g} / \mathrm{L}, 0.4 \mathrm{~g} / \mathrm{L}, 0.6 \mathrm{~g} / \mathrm{L}, 0.8 \mathrm{~g} / \mathrm{L}$ and $1.0 \mathrm{~g} / \mathrm{L})$ of the inhibitor (extract). Also, two tin metal coupons were immersed in $400 \mathrm{ml}$ of $0.5 \mathrm{M} \mathrm{HCl}$ solution without an inhibitor which was used as the control medium. The solutions containing the coupons were then placed in the corrosion kit. Air was passed through the solutions by the aid of the suction motor in the corrosion kit. The solutions experienced turbulence due to the passage of air at low pressure. The experiment was allowed to run for 1hour after which the coupons were removed, cleaned, sandpapered, brushed with acetone and weighed using a beam balance. The experiment was repeated four more times.

\section{E. EXPERIMENTAL RESULTS AND DISCUSSION}

\section{Prolonged Test}

\section{Weight Loss Analysis}

Examination of Figure 1 shows that for a given extract concentration, the weight loss of the tin metal increased with time showing that as time elapsed, the acidic medium was able to penetrate and attack the metal for the inhibited sample but at a very low rate compared to that of the uninhibited (no extract). This shows the action of the Mangifera indica seed extract as an inhibitor. For the uninhibited corrosion process, the intense increase in the weight loss of the samples in the acid medium in the first 13 days of exposure with marginal increase thereafter can be attributed to the initial aggression of the acid on the surface of the tin metal (as a result of the absence of an inhibitor) which later decreased due to the dissolution of some of the metal in the acid media [10].

\section{Corrosion Rate Analysis}

A close examination of Figure 2 shows very low corrosion rate values for all concentrations of the inhibitor. This explains 


\section{International Journal of Engineering Applied Sciences and Technology, 2021 \\ Vol. 5, Issue 10, ISSN No. 2455-2143, Pages 5-10 \\ Published Online February 2021 in IJEAST (http://www.ijeast.com)}

why the inhibition efficiency values are quite high as shown in Figure 3. The profiles also show near-constant corrosion rates for the different inhibitor concentrations. However, a closer examination of the figure shows that the decrease in corrosion rate for the uninhibited sample is much higher than that for the inhibited samples. The near-constant profiles of the inhibited samples therefore indicate the inhibitive effect of the Mapngifera indica seed extract.

\section{Inhibition Efficiency Analysis}

Figure 3 depicts the profiles of the inhibition efficiency of the different inhibitor concentrations. The figure shows that the inhibition efficiency of the extract decreased with time for all the concentrations. It can be inferred that the adsorbed inhibitor molecules were desorbed over time thereby exposing the initially protected metal surface to the corrodent and consequently leading to lower inhibition efficiency values [15, $16,17]$. Also, from the plot, it can be seen that the inhibition efficiencies of the tin metal at different concentrations of the Mangifera indica seed extract are closely compacted and very high. This means that irrespective of the concentration of the extract (considered in this work) in the $0.5 \mathrm{M} \mathrm{HCl}$ acidic medium, Mangifera indica seed extract is a good corrosion inhibitor for tin metal.

\section{Adsorption Isotherm Considerations}

Four different adsorption isotherm models, Langmuir, Freundlich, Temkin and Frumkin adsorption isotherms were used to check the mode of adsorption of the extract. The results obtained showed that the adsorption was best modeled by the Langmuir adsorption Isotherm. Table 1 gives a summary of the Langmuir adsorption isotherm parameters. The linear plot (Figure 4) with high coefficient of determination or $R^{2}$ value of 0.9851 clearly reveals that the surface adsorption process of Mangifera indica seed extract on the tin metal surface obeyed the Langmuir adsorption isotherm. Hence, there was an occurrence of physisorption. Langmuir isotherm assumes monolayer adsorption, localization of the adsorbed extract molecules and formation of a layer of insoluble complex on the metal surface which acts as a barrier between the metal surface and the corrosive medium [18].

Secondly, the value of the free energy of adsorption $\Delta G_{a d s}$ is greater than $-40 \mathrm{~kJ} / \mathrm{mol}$. This again suggests physical adsorption mechanism as asserted by $[19,20]$. In addition, the negativity of this value signifies spontaneous adsorption of the extract.

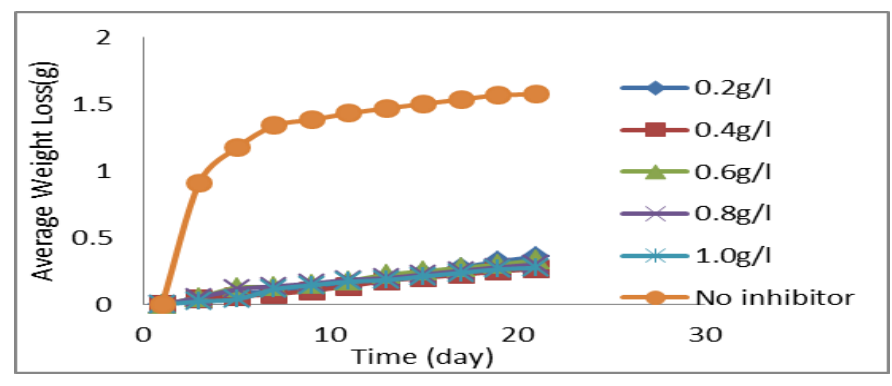

Figure 1: Variation of average weight loss with time of exposure

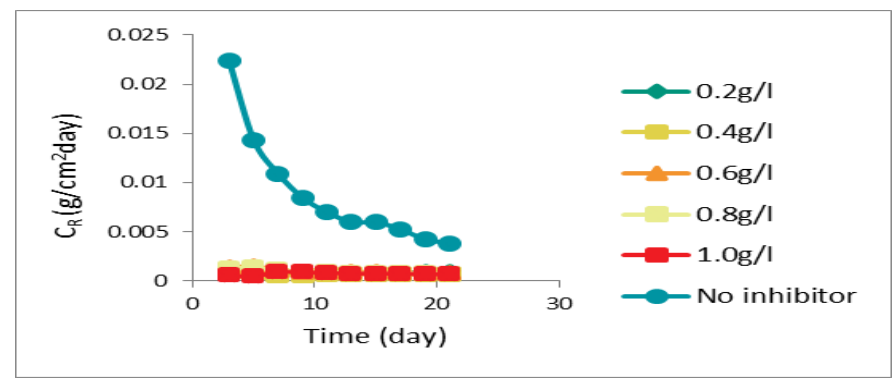

Figure 2: Variation of corrosion rate with time

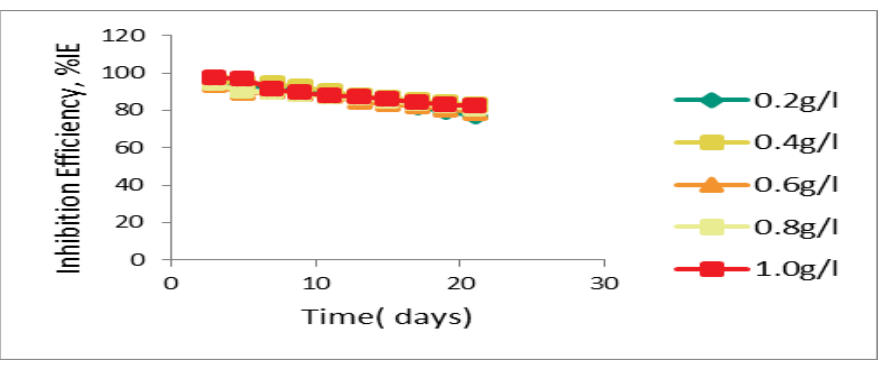

Figure 3: Graph of inhibition efficiency versus time

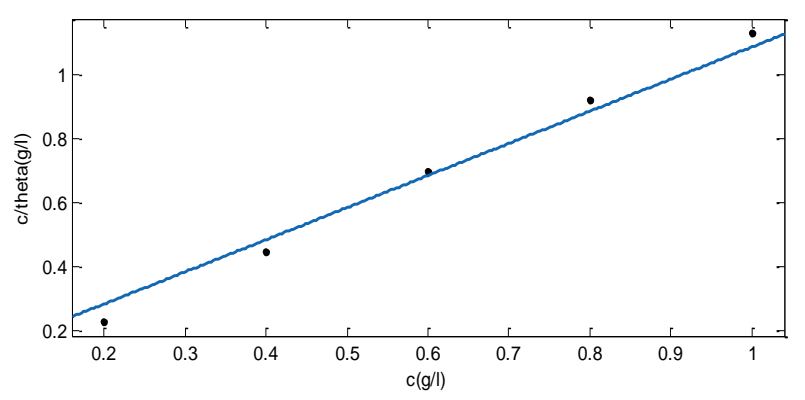

Figure 4: Lngmuir adsortion isotherm

Table 1: Summary of the Isotherm Parameters 


\begin{tabular}{|l|c|c|c|l|}
\hline Isotherm & $\mathrm{R}^{2}$ & Slope & $K_{\text {ads }}$ & $\begin{array}{l}\Delta G_{\text {ads }} \\
(\mathrm{kJ} / \mathrm{mol})\end{array}$ \\
\hline Langmuir & 0.9851 & 1 & 11.85 & -16.079 \\
\hline
\end{tabular}

\section{Rapid Test}

\section{Weight loss analysis}

Figure 5 shows the profiles for the weight loss of the tin metal for the rapid test at various concentrations of the inhibitor and that of the uninhibited sample. It is observed that the loss in weight of the metal increased with time for each of the concentration values considered showing the action of the acid on the metal surface with time. But this attack occurred at a much lower rate for the inhibited samples than for the control sample. This further proves the efficiency of the Mangifera indica seed extract. Also, it is noticed that the difference in weight loss over the 5-hour period of experimentation reduced with increase in inhibitor concentration.

\section{Corrosion Rate Analysis}

It is also observed from Figure 6 that corrosion rate reduced marginally in the first hour of the experiment for all samples after which a marginal increase followed in the next one hour. The corrosion rates then became nearly constant till the end of the experiment. An additional observation is that corrosion rate decreased with inhibitor concentration.

\section{Inhibition Efficiency Analysis}

Examination of Figure 7 shows that the inhibition efficiency of the extract increased marginally in the first hour of the experiment, decreased in the next hour and then became constant for all concentrations. Moreover, it can be seen that increase in the extract concentration led to a corresponding increase in the inhibition efficiency of the Mangifera indica seed extract on the metal. This further confirms the inhibitive effect of the extract on tin metal.

\section{Adsorption and Thermodynamic considerations}

The adsorption data was fit to four different adsorption isotherms (Langmuir, Freundlich, Temkin and Frumkin). The values of the correlation coefficients $\left(\mathrm{R}^{2}\right)$ obtained from the plots showed that the Freundlich adsorption Isotherm was best favoured. Table 2 gives this value and other parameters obtained. The plot (Figure 8) gave a correlation coefficient of 0.9895 . The free energy of adsorption was obtained as $18.666 \mathrm{KJ} / \mathrm{mol}$. This result thus indicates that the corrosion inhibition of the Mangifera indica seed extract is attributed to the adsorption of the phytochemical constituents on the tin metal by a physisorption process, since the value of the free energy ranges from $-20 \mathrm{KJ} / \mathrm{mol}$ to $0 \mathrm{KJ} / \mathrm{mol}$ [21]. The process is also spontaneous since the free energy is negative

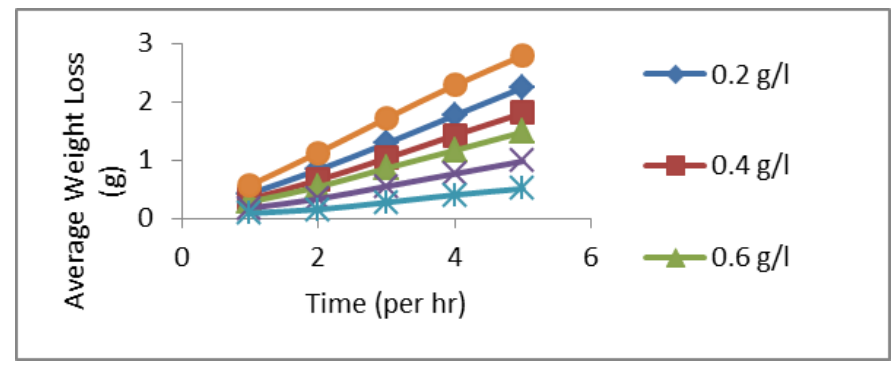

Figure 5: Average weight loss versus time

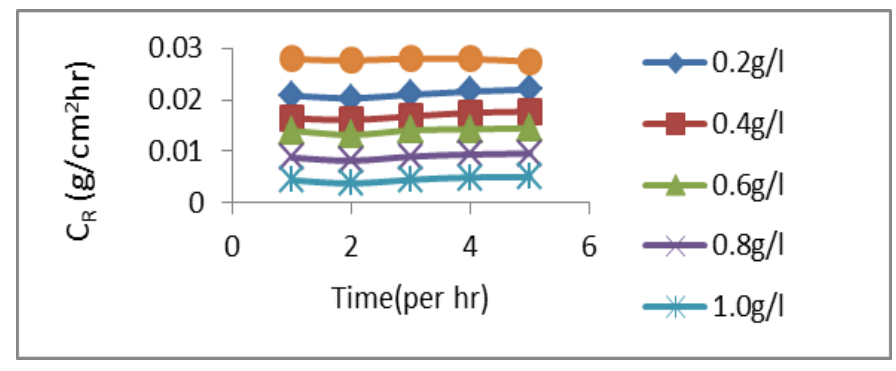

Figure 6: Corrosion rate versus time

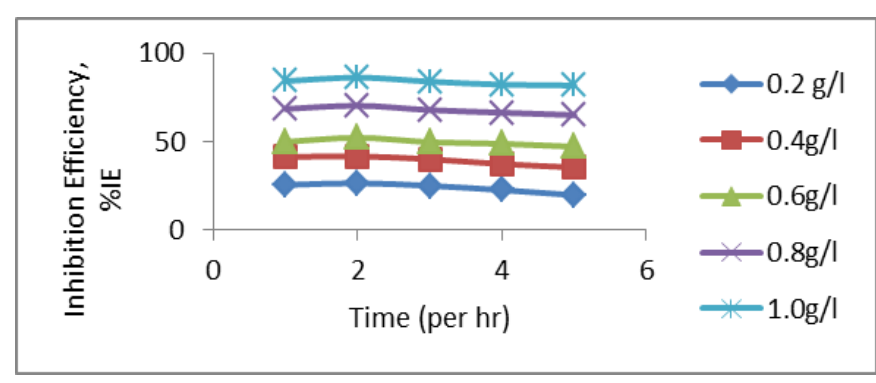

Figure 7: Inhibition Efficiency versus time

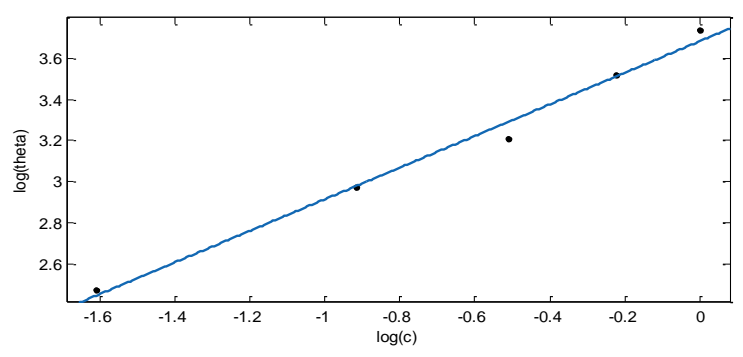

Figure 8: Freundlich Adsorption Isotherm for the gasometric method. 
Table 2: The Summary of the Isotherm Parameters

\begin{tabular}{|l|l|l|l|l|}
\hline Isotherm & $\mathrm{R}^{2}$ & Slope & $K_{\text {ads }}$ & $\Delta G_{\text {ads }}$ \\
& & & & \\
\hline Freundlich & 0.9895 & -0.7668 & 39.77 & -18.666 \\
\hline
\end{tabular}

\section{CONCLUSION}

The present work has shown that Mangifera indica seed extract can be used as corrosion inhibitor on tin metal. As the concentration of the inhibitor increased, the corrosion rate decreased and the inhibitor had a maximum efficiency of $97.4944 \%$ for the prolonged gravimetric test and $84.2294 \%$ for the rapid test respectively, within the range of inhibitor concentration studied, which proved that its usage in the process industries will extremely reduce corrosion rate. If the extract is used as corrosion inhibitor, it will increase the gross domestic product of the Nation and also reduce the emission of harmful substances to the environment

\section{REFERENCE}

[1] Dar M. A (2011). Review: Plant Extracts and Oils as Corrosion Inhibitors in Aggressive Media, Industrial Lubrication and Tribology, (pp. 227- 233).

[2] Ekeke I., Madu I., Nkwoha A and Chiemeka K. (2015) The Effectiveness of Vernonia Amygdalina and Allium Cepa Extract mixture on Mild Steel in Hydrochloric Acid Solution, in International Journal of Engineering and Management Research, (pp. 800 - 805).

[3] Olawale O., Adediran A., Talabi, S., Nwokocha G. and Ameh A. (2017). Inhibitory action of Vernonia amygdalina extract (VAE) on the corrosion of carbon steel in acidic medium, Journal of Electrochemical Science and Engineering, (pp. 145-152).

[4] Yahaya E., Royeun S., Ogunwolu S., Jayeola C. and Igbinadolor, R. (2017). Green and Black Tea (Camellia sinensis) Extracts as Corrosion Inhibitor for Mild Steel in Acid Medium, American-Eurasian Journal of Agricultural and Environmental Science, (pp. 273-279).

[5] Ekeke I., Osoka E., Etim C., Ojiaku C., Eluagu P. and Igwemoh,.H. (2019). Modelling Azadirachta Indica (Neem) Seed Extract-Inhibited Corrosion of Mild Steel and Copper in $\mathrm{H}_{2} \mathrm{SO}_{4}$ medium, Journal of Multidisciplinary Engineering Science and Technology, (pp. 9782-9787).

[6] Loto A. (2001). The Effects of Mango Bark and Leaf Extracts Solution Additives on the Corrosion Inhibition of
Mild Steel in Dilute Sulphuric Acid - Part 2. Corrosion Prevention and Control..

[7] Loto, C. Mohammed A. and Loto R. (2003). Inhibition evaluation of mango juice extracts on the corrosion of mild steel in HCI. Corrosion Prevention and Control, (pp. 107-118).

[8] da Rocha J., Gomes J.. and D'Elia E. (2014). Aqueous EExtracts of Mango and Orange Peel as Green Inhibitors for Carbon Steel in Hydrochloric Acid Solution, Materials Research; (pp. 1581-1587).

[9] Ugi. B., Ekerete J., Ikeuba I and Uwah I. (2015). Mangifera indica Leaves Extracts as Organic Inhibitors on the Corrosion of Zinc Sheet in $5 \mathrm{M} \mathrm{H}_{2} \mathrm{SO}_{4}$ Solution. Applied Science and Environmental Manageent, (pp. 145 $-152,2015)$.

[10] Okoye O., Edeh J. and Obi A. (2015). Corrosion Inhibition Properties of Mangifera indica Seed Extract on Mild Steel, Umudike Journal of Engineering And Technology, (pp. 137-144).

[11] Udonne, J. (2015). Corrosion inhibition study of mild steel in hydrochloric acid using Citrus sinensis and Mangifera indica peel extracts, The Journal of Scientific and Engineering Research, ( pp. 1-7).

[12] Ramezanzadeh M., Bahlakeh G., Sanae Z. and Ramezanzadeh B. (2019). Corrosion inhibition of mild steel in $1 \mathrm{M} \mathrm{HCl}$ solution by ethanolic extract of ecofriendly Mangifera indica (mango) leaves: Electrochemical, molecular dynamics, Monte Carlo and abinitio study. Applied Surface Science, (pp. 1058-1077).

[13] Veedu K., Kalarikkal T., Jayakumar N. and Gopalan, N. (2019). Anticorrosive Performance of Mangifera indica Leaf Extract-Based Hybrid Coating on Steel, ACS Omega, (pp. 10176-10184).

[14] Chen S., Zhu B. and Liang, X. (2020). Corrosion Inhibition Performance of Coconut Leaf Extract as a Corrosion Inhibitor for X65 Steel in Hydrochloric Acid Solution. International Journal of Electrochemical Science, (pp. 1-15)

[15] Oguzie E., Mejeha I., Nwandu M., Okeoma K., Nnanna I., Chidiebere M. and Eze F. (2012). Experimental and Theoretical Assessment of the inhibiting action of Aspilia Afrcana extract on corrosion of aluminum alloy AA3003 in hydrochloric acid. Journal of Materials Science, (pp. $2559-2572$ )

[16] Oguzie E., Adindi C., Enenebeaku C., Ogukwe C., Chidiebere M. and Oguzie K. (2012). Natural products for materials protection: mechanism of corrosion inhibition of mild steel by acid extracts of Piper guineense. Journal of Phyical. Chemistry, (pp. 13603 - 13615).

[17] Chahul, H., Maji, E. and Danat, T. (2019). Adsorptive, inhibitive and thermodynamic studies on the corrosion of mild steel in the presence of Mangifera indica gums. Ovidus University Annals of Chemistry, (pp. 75 - 80). 
[18] Yuli, Y., Emriadi Jamarun and Gunawarman. (2014). Corrosion Inhibition Efficiency of Mild Steel in Hydrochloric Acid by Adding Theobroma cacao Peel Extract, paper presented at International Conference of Biological, Chemical and Environmental Sciences.

[19] Owate L., Lebe N., Dike I. and Nwadiuko O. (2014). Inhibition of Mild Steel Corrosion by Aspilia africana in Acidic Solution, American Journal of Materials Science, (pp. 144-149).

[20] Gbertyo A., Yiase S., Adejo S., Tyohemba G., and Ahile, J. (2014). Thermodynamic, Kinetic and Adsorptive Parameters of Corrosion of Aluminium Using Sorghum bicolor Leaf Extract in $\mathrm{H}_{2} \mathrm{SO}_{4}$. International Journal of Advanced Research in Chemical Science, (pp. 38-46).

[21] Abechi, S. (2018). Studies on the Mechanism of Adsorption of Methylene Blue onto Activated Carbon using Thermodynamic tools, Science World Journal, (pp. 17-19). 